\title{
Review of Under-Five Deaths through Verbal Autopsy in a Rural Block of Haryana
}

\author{
Nitika Sharma*, Neelam Kumar, Srishti Singh, Anuj Jangra
}

\section{Nitika Sharma*, Neelam Kumar, Srishti Singh, Anuj Jangra}

Department of Community Medicine, Pt. B D Sharma PGIMS, Rohtak, Haryana, INDIA.

\section{Correspondence}

\section{Dr Nitika Sharma}

(M.D. Community Medicine) Junior Resident, Department of Community Medicine, Pt B D Sharma PGIMS

Rohtak, Haryana, INIDIA.

Mobile no: 9728588774

Email: 245nitikasharmagmc@gmail.com

\section{History}

- Submission Date: 12-04-2017

- Revised Date: 16-10-2017

- Accepted Date: 10-12-2017

DOI : 10.5530/ijmedph.2018.1.1

Article Available online

http://www.ijmedph.org/v8/i1

\section{Copyright}

(c) 2018 Phcog.Net. This is an openaccess article distributed under the terms of the Creative Commons Attribution 4.0 International license.

\begin{abstract}
Introduction: Under-five mortality rate (U5MR) serves as an indicator for the health and socioeconomic status of a given population. Earlier MDGs and now SDGs pledge to bring down the U5MR. Verbal autopsy enables to make a retrospective enquiry into events leading to death, identify delays contributing to death and establish probable cause of death. This study aimed to compare the determinants and delays leading to infant and child deaths. Methodology: A cross sectional study was carried out in a rural block of district Rohtak from July 2015 to June 2016. All the under-five deaths that took place during study period were reviewed through verbal autopsy using NRHM death review formats. The data collection was done through house-tohouse visits. Data was analysed using SPSS. Results: The infant mortality rate was be 34.1 per 1000 live births and the under-five mortality rate was 38.2 per 1000 live births. Educational and socio-economic status of the parents significantly affected deaths. Accident/injury and diarrhoea were the major causes of child deaths. Conclusion: Factors contributing to the mortality among the under-five children were the lower educational status of parents especially mothers, not practising EBF, inadequate knowledge regarding danger signs among parents, socio- economic barriers to care seeking and cultural beliefs.

Key words: Under-five mortality, Verbal autopsy, Determinants, Care seeking.
\end{abstract}

\section{INTRODUCTION}

Under-five Mortality rate (U5MR) indicates the probability of dying between birth and exactly five years of age, expressed per 1,000 live births, if subject to current mortality rates. ${ }^{1}$ The U5MR is an indicator of health and socio-economic status of a given population and assesses the impact of various intervention programmes aimed at improving the child survival. ${ }^{2}$

Nearly 6 million children under the age of five died in 2015. ${ }^{3}$ The risk of a child dying before completing five years of age is highest in the WHO African Region (81 per 1000 live births) followed by Southern Asia. ${ }^{4}$ According to SRS 2014, the under-five mortality rate in India was 45 per 1000 live births (51 per 1000 live births in rural areas). ${ }^{5}$

The MDG 4 sole target was specifically aimed to bring down the under-five mortality by two thirds between 1990 and 2015. The proposed SDG target 3.2 aims to end preventable deaths of children under five years of age by 2030 to 25 per 1,000 live births. ${ }^{6}$

Most child deaths are caused by diseases that are readily preventable or treatable with proven, cost-effective and quality-delivered interventions. Infectious diseases and neonatal complications are responsible for the vast majority of U5 deaths globally. ${ }^{7}$

Amongst all under 5 deaths in India, prematurity and Low Birth Weight (29.8\%), pneumonia (17.1\%) and diarrheal disease $(8.6 \%)$ are the most common causes of deaths. ${ }^{8}$
Verbal autopsy, a method of obtaining information about a deceased person by asking questions from family and others who can describe the mode of death and circumstances preceding death ${ }^{9}$ can be used as an alternative method for collecting mortality data and establish the cause of death retrospectively. The verbal autopsy, in simpler words, is a tool to identify delay in seeking care, delay in transport or the delay in providing appropriate care at facility and community levels that contributed to childhood illnesses and mortality. Knowledge about causes of death and any vital event is important for public health planning and resource allocation.

Knowledge about causes of death and any vital event is important for public health planning and resource allocation. There is considerable lacuna in vital registration as well as in reporting of the cause of death. ${ }^{10}$

This study was conducted with the objective to compare the various socio-demographic determinants and socio-cultural factors causing delay and contributing to deaths of infants and children under five years of age.

\section{MATERIAL AND METHODS}

A cross sectional study was carried out in a rural block of district Rohtak to review all the under-five child deaths from the period of July 2015 to June 2016. The population of block was 106935 (as enumerated in the annual survey by multipurpose health workers) and it has 3 PHCs and 20 SCs. The estimated
Cite this article : Sharma N, Kumar N, Singh S, Jangra A. Review of Under-Five Deaths through Verbal Autopsy in a Rural Block of Haryana. Int J Med Public Health. 2018;8(1):1-6. 
number of deaths using the birth rate (22.6 per 1000 population $)^{11}$ and U5MR (44 per 1000 live births) ${ }^{11}$ for the rural Haryana came out to be 106. Universal sampling was applied to include all the deaths that took place in the study area during the study duration. Prior ethical approval was obtained from the institutional ethical committee.

All the respondents of the deceased children willing to participate in study were included. Parents, next-of-kin or caregiver who could not be contacted after three visits, not willing for the interview and had moved out of the area were excluded from the study.

A predesigned pretested semi structured schedule used by National Health Mission was used to collect data. A pilot study was carried out to check for the feasibility of the tool. The data was entered in the Microsoft Excel spreadsheet and analysed using SPSS (Statistical Package for Social Studies) version 20.0.

The NHM schedule employs the use of 'verbal autopsy' to identify the probable cause(s), various determinants and delays contributing to death.

The list of children who died during July 2015 to June 2016 was obtained from each sub-centre. The respondents were personally contacted and interviewed by the investigator who was accompanied by the MPHW (F)/ ASHA worker of the respective area.

\section{RESULTS}

In our study, there were 74 under-five deaths (66 infant and 8 child deaths [1-5years]). The total number of live births in the study area during the study duration were 1933 (Birth rate- 18/1000 population). The infant and under-five (U5) mortality rates were 34.1 and 38.2 per 1000 live births respectively.

Among the deceased, 41 (55.4\%) were females and 33 (44.6\%) were males. Majority of the respondents (73\%) were mothers, $21.6 \%$ were fathers and $5.4 \%$ were the other relatives of the deceased.

Table 1 shows that among the deceased infants, in majority, the age of mothers $(62.1 \%)$ and fathers (63.6\%) was between 23-27 years and 25-30 years respectively. Among the deceased infants, the mothers (37.9\%) and fathers $(25.8 \%)$ in majority were illiterate and among child deaths, majority mothers were secondary (37.5\%) and higher secondary level educated (37.5\%) educated and fathers were graduate and above (50\%). $48.5 \%$ infant and $62.5 \%$ child deaths occurred among families lying in the lower middle socio-economic status.

The association between mother's $(\mathrm{p}=0.050)$ and father's education $(p=0.042)$ and type of death was statistically significant. The association between type of death and socio-economic status was statistically significant ( $\mathrm{p}=0.021$ ).

Table 2 shows that among the deceased infant and children, majority (43.9\% and $75 \%$ respectively) had third or higher birth order. Among the infants, majority deaths took place in hospital. $75.8 \%$ of infants and $75 \%$ of children who died were delivered by doctors and the association between type of death and the personnel assisting delivery was statistically significant ( $\mathrm{p}=0.045$ ). The findings for infant mortality could be attributed to the fact that sometimes females in labor get delayed in seeking care and report late to the institutions leading to complications and such deaths when registered in institutions give a spurious information on higher number of deaths in hospitals and among those delivered by health professionals. Majority of the deceased infants (72.7\%) and children (75\%) were born at term.

Birth asphyxia (19.7\%) accounted for majority of infant deaths followed by pneumonia (15.1\%) and complications of preterm delivery (15.1\%) including prematurity and LBW, then congenital diseases (13.6\%), aspiration pneumonia (10.6\%), diarrhoea and infection $9 \%$ each and accident /injury (4.5\%).
It was observed that the major causes of child death were accident/injury and diarrhoea (Figure 1).

In the study, delay in seeking care and delay in transport were assessed and found to be contributing in $79.7 \%$ and $37.8 \%$ cases of deaths. However, the delay at health facility could not be properly assessed as only the view of the caregivers was available, no records of the treatment taken or of the health facility where treatment was taken were available in most of the cases (Table 3 and 4).

On applying the binomial logistic regression on the factors influencing the delay in seeking care, higher odds were observed for prestige and scheduled castes and among those having less than five members in the family.

Table 4 shows that odds for delay in transport were about 72 times higher among the unemployed than employed fathers $(p=0.033)$. Lower odds for delay in transport were also observed among other backward castes, illiterate fathers and families having $<5$ family members.

\section{DISCUSSION}

The present study was carried out in a rural block of district Rohtak and 74 deaths (66 infant and 8 child deaths) were reviewed. The infant and the under-five mortality rates were calculated to be 34.1 and 38.2 per 1000 live births respectively. NFHS-4 Haryana factsheet (2015-16) ${ }^{12}$ reported infant and under-five mortality rate in the rural areas as 33 and 44 per 1000 live births respectively.

Sample Registration System (SRS) $2014^{5}$ reported the infant mortality rate in India as 39 per 1000 live births. Our study findings indicate lower mortality rates than national Figures and it may be difference in the sample size. ${ }^{13}$ In rural area of Aligarh reported infant and under-five mortality rates to be 82.96 and 125.6 per 1000 live births respectively which were higher than our study. It may be due to inaccessible health services and different health seeking behaviour of population in the area of Shah et al.

In our study, the association between mother's age and type of death was statistically significant ( $\mathrm{p}=0.005) .{ }^{14,15}$ Reported lower odds of infant and child mortality with increase in the age. This may be due to better utilization of Maternal and Child Health services by the older mothers. The parents in majority of infant deaths were illiterate and among child deaths, majority mothers were secondary (37.5\%) level educated and fathers were graduate and above (50\%). The association between parents' education and type of death was statistically significant. ${ }^{16}$ Reported that mother's schooling for more than 8 years lowered the odds of infant mortality by $34 \%$. Higher level of education improves the knowledge of parents regarding early care seeking and utilization of health services.

The higher number of infant deaths was seen among the SC (27.3\%) and OBC (28.7\%) and child deaths were more among the prestige caste $(37.5 \%)$ in our study. ${ }^{17}$ Reported that the odds of under-five mortality decreased among OBC caste $(p<0.05)$. The disagreement in the findings can be due to difference in the sample size of the studies and cultural practices of the study populations. In our study, the association between type of death and socio-economic status was statistically significant $(p=0.021) .{ }^{17}$ Reported lower odds of under-five mortality with higher standard of living $(p<0.01)$. Lower number of deaths with increase in socio-economic status may be because of better affordability, access to health facility and improved literacy status.

In our study, among the deceased infant and children, $43.9 \%$ and $75 \%$ respectively had third or higher birth order. In the study by ${ }^{17}$ it was found that the odds of under-five death were lowered with third or higher $(p<0.001)$ order of birth. The association of mortality with birth order may be due to socio-cultural variability. Also with the higher birth order, the fertility choices are influenced more by the family choices rather than 


\begin{tabular}{|c|c|c|c|}
\hline \multirow[t]{2}{*}{ Variable } & \multicolumn{2}{|c|}{ Type of death } & \multirow[t]{2}{*}{ Statistical Test } \\
\hline & Infant & Child & \\
\hline \multicolumn{4}{|l|}{ Mother's Age (in years) $(\mathrm{N}=74)$} \\
\hline $18-22$ & $15(22.7)$ & $0(0.0)$ & \multirow{3}{*}{$\begin{array}{c}\chi^{2}-10.437 \\
p=0.005\end{array}$} \\
\hline 23-27 & $41(62.1)$ & $3(37.5)$ & \\
\hline $28-32$ & $10(15.2)$ & $5(62.5)$ & \\
\hline \multicolumn{4}{|l|}{ Father's Age (in years) $(\mathrm{N}=74)$} \\
\hline 20-25 & $12(18.2)$ & $0(0.0)$ & \multirow{4}{*}{$\begin{array}{c}\chi^{2}-26.984 \\
p<0.01\end{array}$} \\
\hline $25-30$ & $42(63.6)$ & $0(0.0)$ & \\
\hline 30-35 & $8(12.1)$ & $7(87.5)$ & \\
\hline $35-40$ & $4(6.1)$ & $1(12.5)$ & \\
\hline \multicolumn{4}{|l|}{ Educational Status of mothers $(\mathrm{N}=74)$} \\
\hline Illiterate & $25(37.9)$ & $2(25)$ & \multirow{6}{*}{$\begin{array}{c}\chi^{2}-11.087 \\
p=0.050\end{array}$} \\
\hline Primary & $10(15.2)$ & $0(0.0)$ & \\
\hline Middle & $10(15.2)$ & $0(0.0)$ & \\
\hline Secondary & $15(22.6)$ & $3(37.5)$ & \\
\hline Higher Secondary & $4(6.1)$ & $3(37.5)$ & \\
\hline Graduate and above & $2(3)$ & $0(0.0)$ & \\
\hline \multicolumn{4}{|l|}{ Educational Status of Fathers $(\mathrm{N}=74)$} \\
\hline Illiterate & $17(25.8)$ & $1(12.5)$ & \multirow{6}{*}{$\begin{array}{c}\chi^{2}-11.542 \\
p=0.042\end{array}$} \\
\hline Primary & $8(12.1)$ & $0(0.0)$ & \\
\hline Middle & $10(15.2)$ & $0(0.0)$ & \\
\hline Secondary & $16(24.2)$ & $2(25)$ & \\
\hline Higher Secondary & $9(13.6)$ & $1(12.5)$ & \\
\hline Graduate and above & $6(9.1)$ & $4(50)$ & \\
\hline \multicolumn{4}{|l|}{ Socio-economic status $(\mathrm{N}=74)$} \\
\hline Lower & $5(7.6)$ & $3(37.5)$ & \multirow{4}{*}{$\begin{array}{l}\chi^{2}-9.705 \\
p=0.021\end{array}$} \\
\hline Lower Middle & $32(48.5)$ & $5(62.5)$ & \\
\hline Middle & $28(42.4)$ & $0(0.0)$ & \\
\hline Upper Middle & $1(1.5)$ & $0(0.0)$ & \\
\hline \multicolumn{4}{|l|}{ Caste $^{\star \star}(\mathrm{N}=74)$} \\
\hline Scheduled Caste (SC) & $18(27.3)$ & $2(25)$ & \multirow{4}{*}{$\begin{array}{l}\chi^{2}-1.879 \\
p=0.598\end{array}$} \\
\hline Other backward Caste (OBC) & $19(28.7)$ & $2(25)$ & \\
\hline Prestige Caste & $12(18.2)$ & $3(37.5)$ & \\
\hline Dominant Caste & $17(25.8)$ & $1(12.5)$ & \\
\hline \multicolumn{4}{|l|}{ Family Members (N=74) } \\
\hline$<5$ & $25(37.9)$ & $4(50)$ & \multirow{2}{*}{$\begin{array}{l}\chi^{2}-0.440 \\
p=0.507\end{array}$} \\
\hline$>5$ & $41(62.1)$ & $4(50)$ & \\
\hline
\end{tabular}

${ }^{\star}$ Figures in parenthesis represent percentage.

${ }^{*}$ Dominant caste includes the caste to which majority population belongs and prestige caste are other in general category. 


\begin{tabular}{|c|c|c|c|}
\hline \multirow[t]{2}{*}{ Variables } & \multicolumn{2}{|c|}{ Type of death } & \multirow[t]{2}{*}{ Statistical Test } \\
\hline & Infant & Child & \\
\hline \multicolumn{4}{|l|}{ Birth Order $(\mathrm{N}=74)$} \\
\hline First & $13(19.7)$ & $1(12.5)$ & \multirow{3}{*}{$\begin{array}{l}\chi^{2}-2.853 \\
p=0.240\end{array}$} \\
\hline Second & $24(36.4)$ & $1(12.5)$ & \\
\hline Third or Higher & $29(43.9)$ & $6(75)$ & \\
\hline \multicolumn{4}{|l|}{ Place of Death $(N=74)$} \\
\hline Home & $22(33.3)$ & $6(75)$ & \multirow{2}{*}{$\begin{array}{l}\chi^{2}-5.267 \\
p=0.022\end{array}$} \\
\hline Hospital & $44(66.7)$ & $2(25)$ & \\
\hline \multicolumn{4}{|l|}{ Maturity status at Birth (N=74) } \\
\hline Pre-term & $17(25.8)$ & $2(25)$ & \multirow{3}{*}{$\begin{array}{l}\chi^{2}-0.128 \\
p=0.938\end{array}$} \\
\hline Term & $48(72.7)$ & $6(75)$ & \\
\hline Post-tem & $1(1.5)$ & $0(0.0)$ & \\
\hline \multicolumn{4}{|c|}{ The personnel assisting the delivery $(\mathrm{N}=74)$} \\
\hline Doctor & $50(75.8)$ & $6(75)$ & \multirow{4}{*}{$\begin{array}{l}\chi^{2}-8.069 \\
p=0.045\end{array}$} \\
\hline Nurse/Mid-wife & $12(18.2)$ & $0(0.0)$ & \\
\hline Mother by Herself & $2(3)$ & $0(0.0)$ & \\
\hline Other & $2(3)$ & $2(25)$ & \\
\hline \multicolumn{4}{|c|}{ Birthweight of the deceased $(\mathrm{N}=74)$} \\
\hline Normal Weight & $43(65.2)$ & $5(62.5)$ & \multirow{3}{*}{$\begin{array}{l}\chi^{2}-0.022 \\
p=0.882\end{array}$} \\
\hline Low Birth Weight & $23(34.8)$ & $3(37.5)$ & \\
\hline Total & $66(100)$ & $8(100)$ & \\
\hline
\end{tabular}

${ }^{\star}$ Figures in parenthesis represent percentage.

\begin{tabular}{|c|c|c|c|c|}
\hline \multirow[t]{2}{*}{ Variables } & \multirow[t]{2}{*}{ Sig. } & \multirow[t]{2}{*}{ aOR } & \multicolumn{2}{|c|}{ 95\% C.I. for aOR } \\
\hline & & & Lower & Upper \\
\hline \multicolumn{5}{|l|}{ Caste of the Deceased } \\
\hline Scheduled Caste & .0684 & 0.673 & 0.100 & 4.541 \\
\hline Other Backward Caste & 0.100 & 0.246 & .046 & 1.306 \\
\hline Prestige Caste & 0.753 & 0.756 & .132 & 4.321 \\
\hline \multicolumn{5}{|l|}{ Dominant Caste ${ }^{*}$} \\
\hline \multicolumn{5}{|l|}{ Literacy Status of Father } \\
\hline Literate & .045 & .069 & .005 & 0.943 \\
\hline \multicolumn{5}{|l|}{ Illiterate ${ }^{*}$} \\
\hline \multicolumn{5}{|c|}{ Family Members } \\
\hline$>5$ & .315 & .405 & .070 & 2.358 \\
\hline \multicolumn{5}{|l|}{$\leq 5^{*}$} \\
\hline \multicolumn{5}{|c|}{ Occupational Status of Father of the Deceased } \\
\hline Unemployed & .033 & 72.795 & 1.418 & 37.381 \\
\hline \multicolumn{5}{|l|}{ Employed* } \\
\hline \multicolumn{5}{|l|}{ Sex of the deceased } \\
\hline Male & .487 & 0.629 & .170 & 2.323 \\
\hline Female* & & & & \\
\hline
\end{tabular}

${ }^{\star}$ Reference Category 


\begin{tabular}{|c|c|c|c|c|}
\hline \multirow[t]{2}{*}{ Variables } & \multirow[t]{2}{*}{ Sig. } & \multirow[t]{2}{*}{ aOR } & \multicolumn{2}{|c|}{$95 \%$ C.I. for aOR } \\
\hline & & & Lower & Upper \\
\hline \multicolumn{5}{|l|}{ Caste of the Deceased } \\
\hline Scheduled Caste & 0.062 & 10.495 & .890 & 123.781 \\
\hline Other Backward Caste & .103 & 4.291 & .746 & 24.675 \\
\hline Prestige Caste & .022 & 19.137 & 1.541 & 237.631 \\
\hline \multicolumn{5}{|l|}{ Dominant Caste ${ }^{*}$} \\
\hline \multicolumn{5}{|l|}{ Literacy status of Father } \\
\hline Literate & .730 & .552 & .019 & 16.221 \\
\hline Illiterate & & & & \\
\hline \multicolumn{5}{|l|}{ Family members } \\
\hline$>5$ & .853 & 1.196 & .180 & 7.970 \\
\hline$\leq 5^{*}$ & & & & \\
\hline
\end{tabular}

${ }^{*}$ Reference Category

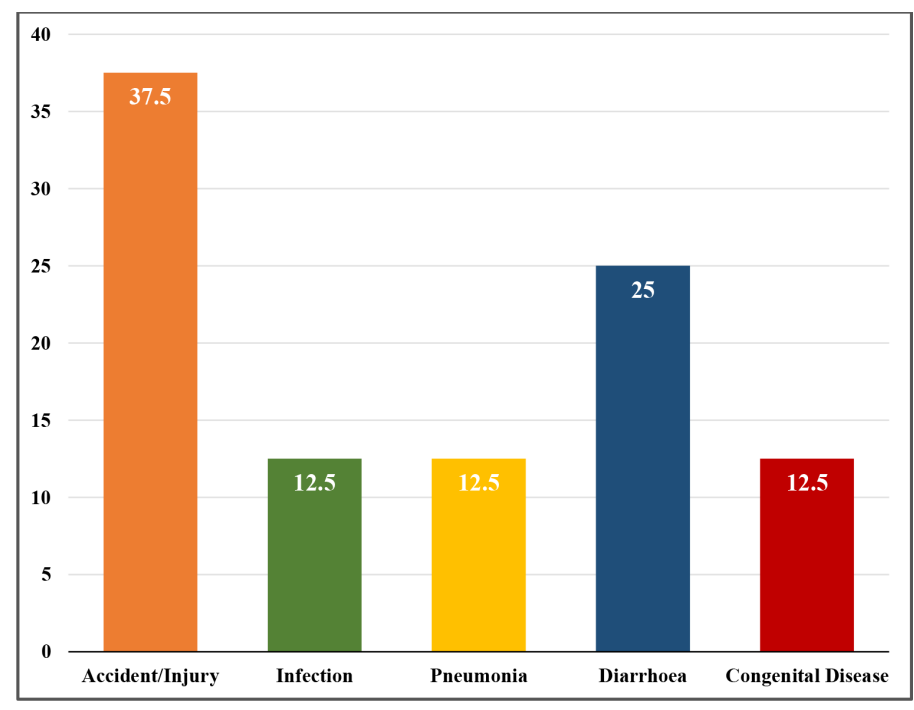

Figure 1: Probable Causes of Child Death (in Percentage).

age and educational status of the parents. Out of the deceased infants, $34.8 \%$ had low birth weight. ${ }^{18,9}$ the percentage of LBW in rural areas was 13.6 and 15.8 respectively which was lower than our study. In the study by, ${ }^{20} 69.4 \%$ were born LBW. The difference in the compliance to the advice by healthcare providers, poor nutritional status and dietary habits of expectant mothers may be the possible reasons.

Birth asphyxia (19.7\%), pneumonia (15.1\%) and complications of preterm delivery (15.1\%) including prematurity and LBW were the major causes of infant death in our study. A report by Registrar General of India on cause of death $2010-13^{8}$ enumerated birth asphyxia and birth trauma, pneumonia, prematurity and LBW as the major causes of infant deaths. Among the major causes of child death were accident/injury (37.5\%), infection (12.5\%), pneumonia (12.5\%), diarrhoea (25\%) and congenital diseases (12.5\%). In the study by, ${ }^{21}$ major causes of under-five death were diarrhoea (20.5\%) followed by ARI (17.7\%).

In our study, it was found that in $79.8 \%$ of the deceased, there was delay in seeking care, delay in transport was reported in $37.8 \%$ of the deceased by the respondents. In the study by, ${ }^{21}$ among the post-neonatal deaths the delay in seeking care was seen for $42.3 \%$, the delay in transport in $46 \%$ and the delay at health facility in $49.2 \%$ of the deceased. In the study by, ${ }^{22}$ the delay in seeking care was observed among $82.2 \%$, delay among transport in $56 \%$ and delay at health facility among $36.4 \%$ of the underfive deaths. The difference in the findings of our study from these studies can be because of the different sample sizes analysed, socio-economic inequalities and differences in cultural, educational and occupational status of the parents.

\section{CONCLUSION}

The educational status of parents, socio-economic status of the family and the personnel attending delivery were the key determinants of the under-five deaths in the study area. Birth asphyxia, pneumonia and complications of preterm delivery were the major causes of infant death and accident/injury, infection, pneumonia and diarrhoea contributed mostly to the child deaths. Various socio-cultural delays contributing to the deaths. Most of the under five children deaths can be prevented by regular and effective training programmes for health care providers and pregnant females whereas early recognition of danger signs and early referral system can save many precious lives.

\section{ACKNOWLEDGEMENT}

The authors acknowledge the co-operation of relatives of the deceased on the sensitive issue studied.

\section{CONFLICT OF INTEREST}

The authors declare that there is no conflict of interest.

\section{ABBREVIATIONS USED}

U5MR: Under-five Mortality Rate; WHO: World Health Organization; SRS: Sample Registration System; MDG: Millennium Development Goals; SDG: Sustainable Development Goals; PHC: Primary Health Centre; SC: Sub Centre; MPHW: Multi-Purpose Health worker.

\section{REFERENCES}

1. World Health Organization. Definitions: Emergencies [Internet]. Geneva: WHO. 2013. [Cited 2016 Oct 10]. Available from: http://www.who.int/hac/about/defini- 
tions/en/

2. National Institute of Medical Statistics, Indian Council of Medical Research and UNICEF. Infant and child mortality in India: Levels, Trends and Determinants [Internet]. NIMS, ICMR and UNICEF. New Delhi. 2012. [Cited 2016 Sep 16]. Available from: http://unicef.in/Uploads/Publications/Resources/pub doc35.pdf Word Health Organisation. Children: Reducing mortality. WHO Fact sheet [Internet]. Geneva: WHO; 2016 January [Cited 2016 September 6]. Available from: http://www.who.int/mediacentre/factsheets/fs178/en.

3. UNICEF. Levels and Trends of Maternal and Child mortality: Report 2015 [Internet]. New York: 2015 [Cited 2016 Sep 14]. Available from: http://www.childmortality.org/files_v20/download/IGME\%20Report\%202015_9_3\%20LR\%20 Web.pdf

4. Sample Registration System Bulletin 2014. Chapter- 4 Estimates of Mortality Indicators [Internet]. Office of the Registrar General. Ministry of Home Affairs, Government of India. [Cited 2016 September 14]. Available from: http://www. censusindia.gov.in/vital_statistics/SRS_Report_2014/8.\%20Chap\%204-Mortality $\% 20$ Indicators-2014.pdf

5. World Health Organization. Levels and Trends of Maternal and Child mortality: Report 2015 [Internet]. Geneva: 2015 [Cited 2016 September 14] Available from: http://www.childmortality.org/files_v20/download/IGME\%20Report\%20 2015_9_3\%20LR\%20Web.pdf

6. UNICEF. Levels and Trends of Maternal and Child mortality: Report 2015. New York: 2015 [Internet] [Cited 2016 Sep 14]. Available from: http://www.childmortality. org/files_v20/download/IGME\%20Report\%202015_9_3\%20LR\%20Web.pdf

7. Registrar General of India and Centre for Global Health Research. Joint report on cause of death statistics 2010-2013 [Internet]. 2015 [Cited 2016 September 14]. Available from: http://www.cghr.org/wordpress/wp-content/uploads/COD-IndiaReport-2010-2013-Dec-19-2015.pdf

8. Child death review- Operational guidelines [Internet]. Ministry of Health and Family Welfare, Government of India. 2014 Aug. [Cited 2016 Sep 16]. Available from: http://nrhm-components/rmnch-a/maternal-health/guidelines.html

9. Jha P. Reliable mortality data: a powerful tool for public health. Natl Med J India. $2001 ; 14(3): 129-31$.

10. Sample Registration System Bulletin 2014. SRS statistical report tables [Internet] Office of the Registrar General. Ministry of Home Affairs, Government of India. [Cited 2016 Sep 14]. Available from: http://w ww.censusindia.gov.in/vital statistics/SRS_Report_2014/9.\%20SRS\%20Statistical\%20Report\%20-Detailed\%20 tables-2014.pdf

11. Ministry of Health and Family Welfare. National Family Health Survey-4: State factsheet Haryana [Internet]. International Institute for Population Sciences. Mumbai: 2015-16 [Cited 2016 September 12]. Available from: http://rchiips.org/
nfhs/pdf/NFHS4/HR_FactSheet.pdf

12. Shah MS, Khalique N, Khan Z. Determinants of childhood mortality. Indian J Prev Soc Med 2011; 42(2):118-22.

13. Kembo J, Ginneken JKV. Determinants of infant and child mortality in Zimbabwe: results of multivariate hazard analysis. Demographic Research [Internet]. 2009 [Cited 2016;21(13):367-84. Available from: http://www.demographic-research. org/volumes/vol21/13/21-13.pdf. doi: 10.4054/DemRes.2009.21.13.

14. Sahu D, Nair S, Singh L, Gulati BK, Pandey A. Levels, trends and predictors of infant and child mortality among Scheduled Tribes in rural India. ICMR, New Delhi. Indian J Med Res. 2015;141(5):709-19.

15. Chandhiok N, Singh L, Singh KJ, Sahu D, Pandey A. Does breastfeeding have an effect on infant mortality in India. An analysis of National Family Health survey Data. Open Journal of Preventive Medicine [Internet]. 2015;5(9):359-69. Available from: http://file.scirp.org/pdf/OJPM_2015091611264436.pdf. DOI: 10.4236/ojpm.2015.59040.

16. Singh R, Tripati V. Under-five mortality among mothers employed in agriculture: findings from a nationally representative sample. Peer J. 2015;3:710. DOI 10.7717/peerj. 710

17. Ministry of Health and Family Welfare. District Level Household and Facility Survey-4: State factsheet Haryana [Internet]. International Institute for Population Sciences. Mumbai: 2012-13. Available from: http://rchiips.org/pdf/dlhs4/ report/HR.pdf

18. Ministry of Health and Family Welfare. District Level Household and Facility Survey-4: District factsheet Rohtak [Internet]. International Institute for Population Sciences. Mumbai. 2012-13. [Cited 2016 September 12]. Available from: https:// nrhm-mis.nic.in/DLHS4/State\%20and\%20District\%20Factsheets/Haryana/ District\%20Factsheets/Rohtak.pdf

19. Damghanian M, Shariati M, Mirzaiinajmabadi K, Yunesian M, Emamian MH Socioeconomic inequality and its determinants regarding infant mortality in Iran. Iran Red Crescent J. [Internet]. 2014;16(6):17602. Available from: https:// www.ncbi.nlm.nih.gov/pmc/articles/PMC4102981/pdf/ircmj-16-17602.pdf. doi: 10.5812/ircmj.17602.

20. Deshmukh V, Lahariya C, Krishnamurthy S, Das MK, Pandey RM, Arora NK. Taken to health care provider or not, underfive children die of preventable causes: Findings from cross-sectional survey and social autopsy in Rural India. Indian J Community Med 2016;41(2):108-19

21. Mahajan V, Kaur A, Sharma A, Azad C, Guglani V. Modifiable factors for prevention of childhood mortality. Indian Pediatr. 2014;51:45-7.

Cite this article : Sharma N, Kumar N, Singh S, Jangra A. Review of Under-Five Deaths through Verbal Autopsy in a Rural Block of Haryana. Int J Med Public Health. 2018;8(1):1-6. 